\title{
Angioma serpiginosum in zosteriform distribution on abdomen: a rare presentation
}

\author{
Kamal Acharya ${ }^{1}$, Prajwal Pandey ${ }^{1}$, Rajan Shah ${ }^{1}$, Muna Bista $^{2}$, and Sameer Shrestha ${ }^{1}$ \\ ${ }^{1} \mathrm{BP}$ Koirala Institute of Health Sciences \\ ${ }^{2}$ Sindhuli District Hospital
}

January 20, 2021

\begin{abstract}
Angioma serpiginosum is a rare benign nevoid disorder affecting the small vessels of the upper dermis. We are presenting a case of this rare disease in an 11-year-old girl who presented with this condition on abdomen in zosteriform pattern which is rare presentation and is the first of its type.
\end{abstract}

\section{Angioma serpiginosum in zosteriform distribution on abdomen: a rare presentation}

Acharya K.P ${ }^{1}$, Pandey $\mathrm{P}^{2}$, Shah $\mathrm{R}^{3}$, Bista $\mathrm{M}^{4}$, Shrestha $\mathrm{S}^{1}$

${ }^{1}$ Junior Resident, ${ }^{2}$ Assistant Professor, Department of Dermatology and Venerology,

${ }^{3}$ Assistant Professor, Department of Pathology, B.P. Koirala Institute of Health Sciences, Dharan, Nepal

${ }^{4}$ Dermatologist, Sindhuli District Hospital

\section{Abstract}

Angioma serpiginosum is a rare benign nevoid disorder affecting the small vessels of the upper dermis. We are presenting a case of this rare disease in an 11-year-old girl who presented with multiple progressive asymptomatic scattered and confluent punctate erythematous to violaceous macules over the left side of the abdomen in T8-T10 dermatomal distribution with normal surrounding and intervening skin since birth. Histopathological examination (HPE) revealed few ectatic congested thin-walled blood vessels in papillary dermis with few areas of downward growth of the rete ridges between these blood vessels. Based on the clinical and the HPE, a diagnosis of angioma serpiginosum was made. This rare vascular anomaly and abdomen involvement with zosteriform distribution is rarely reported in the literature.

\section{Keywords: Angioma Serpiginosum, Zosteriform}

\section{Introduction}

Angioma serpiginosum is a rare benign primary telangiectatic disorder affecting the capillaries of the upper dermis characterized by asymptomatic pinpoint macules that group together in linear, serpiginous, or gyrate patterns. ${ }^{1,2}$ It usually starts in childhood or early adolescence and has female pre-dominance. Most cases are sporadic however few cases may be familial. The exact pathophysiology of this condition is unknown. It is more common in the extremities and gluteal region. There are few case reports of the condition involving palms, soles, mucosa, and chest. However, this is the first case report of the condition involving the abdomen.

\section{Case presentation}


An 11-year-old girl presented with multiple asymptomatic erythematous lesions on the left abdomen which was first noticed by her mother as multiple red pinhead-sized lesions during birth. The lesions progressively extended with new satellite lesions appearing around the previous lesions with the increase in age of the child. There was no family history of similar skin lesions. There were no visual or neurological symptoms.

Cutaneous examination revealed multiple discrete and confluent punctate erythematous to violaceous macules on the left abdomen in T8 to T10 dermatomal distribution with normal surrounding and intervening skin (Figure 1). There was no similar lesion in other parts of the body. Her general physical and systemic examination was unremarkable.

Skin biopsy taken from the lesion showed epidermis with basket weave hyperkeratosis, papillomatosis, and hypogranulosis. Papillary dermis showed few ectatic congested thin-walled blood vessels. Few areas showed downward growth of the rete ridges between these blood vessels. Epidermal changes in the form of acanthosis and extravasation of RBCs, inflammatory cell infiltration, and hemosiderin deposition were not seen in the dermis (Figure 2a, 2b). Based on the clinical and histopathological findings (HPE), a diagnosis of angioma serpiginosum was made.

The patient and her parents were counseled about the benign nature of the disease and planned for laser therapy if any cosmetic concerns in the future.

\section{DISCUSSION}

Angioma serpiginosum (AS) is a rare vascular disorder described first by Hutchinson in 1889 as a "serpiginous or infective nevus" and then named by Crocker in $1894 .{ }^{2,3}$ Cases are usually sporadic, however familial cases with an autosomal dominant or X linked dominant inheritance and few cases with PORCN gene mutation or deletion have been reported. ${ }^{4}$ Angioma serpiginosum results from the proliferation of endothelial cells resulting dilated capillaries. There are various theories regarding its pathogenesis. One of the theories suggesting the role of estrogen while another theory calming the role of cold temperature in its pathogenesis. However, both of the theories are not accepted universally. ${ }^{7,8}$

The condition usually starts in childhood or birth with a female predominance. ${ }^{5,6}$ This condition presents as asymptomatic multiple, pinpoint violaceous or erythematous macules, non-blanching and clustered in an area or form a large sheets distributed in serpiginous, linear (Blaschkoid distribution) or annular pattern. ${ }^{1}$ Lesions are typically unilateral and located predominantly on the lower limbs and extremities but can be extensive. ${ }^{5,9}$ However, palms, soles, mucosal, and truncal involvement is rare. Few cases with segmental truncal and mono-lateral plantar area involvement have been reported. ${ }^{6,10,11,12,13,14}$ This condition progresses slowly and usually attains stability at puberty with some partial spontaneous resolution in late adulthood. The diagnosis is usually made clinically that is confirmed by histological findings of distended ectatic capillaries lined by flattened endothelium cells of normal appearance and the absence of inflammation, erythrocyte extravasations, and hemosiderin deposition. ${ }^{15}$ Treatment is only indicated for cosmetic reasons for which vascular laser is the best option.

In our case, the patient presented with localized telangiectasia without skin atrophy. The differentials for the condition include Angioma serpiginosum, capillary malformation, unilateral nevoid telangiectasia, and purpuric conditions. ${ }^{17}$ Presence of the lesions since birth as unilateral, asymptomatic erythematous, pinpoint to pinhead-sized non blanchable macules and papules in the zosteriform pattern (T8-T10) without atrophy and perilesional halo supports the diagnosis of angioma serpiginosum. The histological findings confirmed the diagnosis. The peculiarity about our case is the site of lesion. This is the first case as per our knowledge with presentation of the lesion on abdomen. In our case, the parents were not concerned about the lesions so, no treatment was given and asked for follow-up later in case of cosmetic concerns.

\section{REFERENCES}

1. Namazi MR, Handjani F. Angioma serpiginosum. Dermatol Online J2003;9:19.

2. Hutchinson J. A peculiar form of serpiginous and infective naevoid disease. Arch Surg. 1889;1:275

3. Radcliffe Crocker H. Diseases of the skin. Philadelphia (PA): Blakiston's Press; 1905: 646. 
4. Lombardi MP, Bulk S, Celli J, Lampe A, Gabbett MT, Ousager LB, van der Smagt JJ, Soller M, Stattin EL, Mannens MA, Smigiel R. Mutation update for the PORCN gene. Human mutation. 2011 Jul;32(7):723-8.

5. Agrawal S, Agarwalla A, Rizal A, Sinha A, Debbarman K. Angioma serpiginosum: a case report. International journal of dermatology. 2004;43(12):917-8.

6. Savant SS, Das A, Kumar P, Hassan S. Late-onset Segmental Angioma Serpiginosum. Indian J Dermatol. 2016;61:226-227

7. Erbagci Z, Erbagci I, Erkiliç S, Bekir N. Angioma serpiginosum with retinal involvement in a male: a possible aetiological role of continuous cold exposure. J Eur Acad Dermatol Venereol. 2004;18:238-239

8. Bayramgurler D, Filinte D, Kiran R. Angioma serpiginosum with sole involvement. Eur J Dermatol2008;18:708-9

9. Katta R, Wagner A. Angioma serpiginosum with extensive cutaneous involvement. J Am Acad Dermatol. 2000;42:384-385.

10. Chen JH, Wang KH, Hu CH, Chiu JS. Atypical angioma serpiginosum. Yonsei Med J2008;49:509-13

11. Sandhu K, Gupta S. Angioma serpiginosum: report of two unusual cases. Journal of the European Academy of Dermatology and Venereology. 2005 Jan;19(1):127-8.

12. Jakhar D, Pandhi D, Singal A, Sharma S. Angioma serpiginosum in a bilateral distribution with acral involvement: an uncommon presentation. Indian J Dermatol Venereol Leprol. 2018;84:338-341

13. Freites-Martinez A, Moreno-Torres A, Núnez AH, Martinez-Sanchez D, Huerta-Brogeras M, Borbujo J. Angioma serpiginosum: report of an unusual acral case and review of the literature. An Bras Dermatol. 2015;90:26-28

14. Bayramgurler D, Filinte D, Kiran R. Angioma serpiginosum with sole involvement. Eur J Dermatol. 2008;18:708-709

15. Requena L, Sangueza OP. Cutaneous vascular proliferation. Part II. Hyperplasias and benign neoplasms. J Am Acad Dermatol. 1997;37:887-919

16. Madan V, August PJ, Ferguson JE. Pulsed-dye laser treatment of angioma serpiginosum. Clinical and Experimental Dermatology: Clinical dermatology. 2009 Jul;34(5):e186-8

17. Ruchi Gupta and et.al. A clinical approach to diagnose patients with localized telangiectasia. International Journal of Dermatology.2015;54:e294-301.

\section{Hosted file}

Figure. docx.pdf available at https://authorea.com/users/390818/articles/505044-angiomaserpiginosum-in-zosteriform-distribution-on-abdomen-a-rare-presentation 